\title{
PENGECEKAN KELAYAKAN BANGUNAN GEDUNG SMA NEGERI 1 KOTA KEDIRI YANG DIGUNAKAN UNTUK AKTIFITAS BELAJAR
}

\author{
Agata Iwan Candra ${ }^{1}$, Yosef Cahyo ${ }^{2}$, Ahmad Ridwan ${ }^{3}$, Sigit Winarto $^{4}$, Edy Gardjito $^{5}$, \\ Eko Siswanto ${ }^{6}$ \\ Prodi Teknik sipil, Fakultas Teknik, Universitas Kadiri \\ ${ }^{1}$ Korespodensi : iindiecom@gmail.com
}

\begin{abstract}
ABSTRAK
Hammer test merupakan bagian dari pengecekan kelayakan dari sebuah bangunan struktur gedung, jembatan, ataupun bangunan struktur yang berhubungan dengan beton. Pada salah satu bangunan existing Sekolah Menengah Atas Negeri 1 Kediri yang akan dilakukan renovasi dan penambahan lantai terdapat retakan - retakan yang terlihat seperti pada kolom, pelat atap dan tembok. Adanya keretakan tersebut dapat mempengaruhi pengambilan tindakan terkait renovasi bangunan tersebut, apakah harus membongkar total banguna tersebut atau hanya melakukan penambalan pada bagian struktur yang mengalami keretakan. Dari data-data yang diambil dari lapangan dapat disimpulkan bahwa pengecekan kelayakan banguan sekolah menengah atas negeri 1 kota kediri diambil dari kekuatan pelat atap dan balok penyangga pelat dengan menggunakan hammer test, maka didapatlah nilai dari perhitungan, $\mathrm{Fc}^{\prime}$ rencana pelat senilai 20,75 M pa atau $250 \mathrm{Kg} / \mathrm{cm}^{2}$ dan untuk $\mathrm{Fc}^{\prime}$ rencana balok senilai $\mathrm{Mpa}$ atau $250 \mathrm{Kg} / \mathrm{cm}^{2}$ sedangkan hasil yang diperoleh dari lapangan untuk perhitungan pelat senilai $280,23 \mathrm{Kg} / \mathrm{cm}^{2}$ yang berarti lebih besar dari nilai rencana, dan untuk perhitungan balok hanya mencapai $234,37 \mathrm{Kg} / \mathrm{cm}^{2}$ yang berarti di bawah nilai yang di rencanakan yaitu $250 \mathrm{Kg} / \mathrm{cm}^{2}$
\end{abstract}

Kata Kunci : Hammer test, SMAN 1 Kediri

\section{PENDAHULUAN}

\section{AnalisisSituasi}

Hammer test merupakan bagian dari pengecekan kelayakan dari sebuah bangunan struktur gedung, jembatan, ataupun bangunan struktur yang berhubungan dengan beton. Pengevckan pada struktur bangunan dengan menggunakan hammer test akan terlaksana dengan baik apabila dilakukan dengan tim yang solid. DidalamSNI-03-4803-1998 Metode Angka Pantul Beton Yang Sudah Mengeras Bab 2.1.b disebutkan, metode ini tidak dimaksudkan sebagai alternatif untuk menetapkan kekuatan beton. Untuk mendapatkan hasil yang optimal, sni-03-4803-1998 hammer test harus dikorelasikan dengan uji core drill test pengeboran. 
Pada salah satu bangunan existing Sekolah Menengah Atas Negeri 1 Kediri yang akan dilakukan renovasidan penambahan lantai terdapat retakan - retakan yang terlihat seperti pada kolom, pelat atap dan tembok. Adanya keretakan tersebut dapat mempengaruhi pengambilan tindakan terkait renovasi bangunan tersebut, apakah harus membongkar total banguna tersebut atau hanya melakukan penambalan pada bagian struktur yang mengalami keretakan. Penyuluhan ini diselenggarakan dengan tujuan membantu mengetahui bahwa banguan yang ada apakah masih layak digunakan untuk kegiatan belajar mengajar.

\section{Permasalahan Mitra}

Mengacu pada uraian analisis situasi persoalan prioritas pada gedung Sekolah Menengah Atas 1 kota kedirimaka dilakukan penyuluhan tentang pengetesan hammer test pada gedung sekolah dengan tujuan kelayakan untuk melakukan pembangunan selanjutnya. Hal ini dilakukan karena terjadi retakan pada sebagian dari bangunan atau kolom dan balok bangunan.

\section{METODE PELAKSANAAN}

1. Letakkan ujung plunger yang terdapat pada ujung alat hammer test pada titik yang akan ditembak dengan memegang hammer dengan arah tegak lurus atau miring bidang permukaan beton yang akan ditest.

2. Plunger ditekan secara perlahan - lahan pada titik tembak dengan tetap menjaga kestabilan arah dari alat hammer. Pada saat ujung plunger akan lenyap masuk kesarangnya akan terjadi tembakan oleh plunger terhadap beton, dan tekan tombol yang terdapat dekat pangkal hammer.

3. Lakukan pengetesan terhadap masing-masing titik tembak yang telah ditetapkan semula dengan cara yang sama.

4. Kemudian data lentingan hasil hammer test pada tiap titik dianalisa sesuai dengan SNI Yang telah saya sebutkan diatas.

\section{JADWAL KEGIATAN}

Berikut jadwal kegiatan pemeriksaan bangunan dan penyuluhan. 
Tabel 4.1 Jadwal kegiatan pengabdian masyarakat

\begin{tabular}{c|l|lll|ll}
\multirow{2}{*}{ No } & \multicolumn{1}{|c|}{ Nama Kegiatan } & \multicolumn{4}{|c}{ Hari Ke } \\
\cline { 3 - 5 } & & 1 & 2 & 3 & 4 & 5 \\
\hline 1 & Penyusunan dan penggandaan materi & & & & \\
2 & Penentuan jadwal penyuluhan dan koordinasi & & & & \\
3 & Pelaksanaan kegiatan & & \\
\hline 4 & Evaluasi dan penyusunan laporan & & &
\end{tabular}

\section{PELAKSANAAN KEGIATAN}

Penyuluhan tentang pengetesan kelayakan bangunan dengan menggunakan alat hammer test yang dilaksanakan pada :

$\begin{array}{ll}\text { Hari / Tanggal } & : \text { Senin / 10 Desember } 2018 \\ \text { Pukul } & : 14: 00-\text { sampai selesai } \\ \text { Tempat } & : \text { SMAN 1 Kota Kediri } \\ \text { Agenda } & : \text { Penyuluhan Evaluasi dan Diskusi }\end{array}$

Kegiatan pengabdian berupa penyuluhan dan evaluasi kepada kepala sekolah dbeserta staf sekolah menengah atas negeri 1 kota kediri mengenai kelayakan gedung sekolah agar bisa digunakan terus untuk kegiatan belajar mengajar. Daftar hadir peserta pada kegiatan tersebut ada pada Lampiran1. Dokumnetasi kegiatan terlampir pada Lampiran 2.

\section{Hasil Kegiatan Dan Perhitungan}

Dari kegiatan pengetesan dan analisi lapangan diperoleh data-data perhitungan hammer test sebagai berikut; 
Tabel 5.1 Data Hammer Test Pada Tiap Elemen Struktur

\begin{tabular}{|c|c|c|c|c|c|}
\hline \multirow{2}{*}{\multicolumn{2}{|c|}{$\begin{array}{c}\text { ELEMEN STRUKTUR } \\
\text { SUDUT PUKULAN }\end{array}$}} & \multicolumn{2}{|c|}{ PELAT } & \multicolumn{2}{|c|}{ BALOK } \\
\hline & & $+90^{\circ}$ & $-90^{\circ}$ & $0^{\circ}$ & $+90^{\circ}$ \\
\hline \multicolumn{2}{|c|}{ KODE BIDANG UJI } & P1 & $\mathbf{P 2}$ & B1 & B2 \\
\hline \multirow{10}{*}{$\begin{array}{c}\text { NILAI } \\
\text { LENTING } \\
\text { PALU BETON } \\
\text { (R) }\end{array}$} & 1 & & 20 & 28 & 36 \\
\hline & 2 & 40 & 18 & 28 & \\
\hline & 3 & 42 & 19 & & 33 \\
\hline & 4 & 36 & 18 & & 31 \\
\hline & 5 & 36 & 20 & 30 & 30 \\
\hline & 6 & 40 & & 30 & 30 \\
\hline & 7 & 38 & 22 & 30 & 34 \\
\hline & 8 & 38 & 20 & 30 & \\
\hline & 9 & & 20 & 30 & 32 \\
\hline & 10 & 40 & 22 & 34 & 30 \\
\hline \multicolumn{2}{|l|}{ R MAKSIMUM } & 42 & 22 & 34 & 36 \\
\hline \multicolumn{2}{|l|}{ R MINIMUM } & 36 & 18 & 28 & 30 \\
\hline \multicolumn{2}{|c|}{ R RATA - RATA } & 38,75 & 19,89 & 30,00 & 32,00 \\
\hline \multicolumn{2}{|c|}{ SIMPANGAN BAKU } & 2,12 & 1,45 & 1,85 & 2,20 \\
\hline \multicolumn{2}{|c|}{ KOEF. VARIASI } & 4,50 & 2,11 & 3,43 & 4,86 \\
\hline \multicolumn{2}{|c|}{$\begin{array}{l}\text { PERKIRAAN KUAT } \\
\text { TEKAN BETON } \\
\text { TERKOREKSI } \\
\left(\mathrm{kg} / \mathrm{cm}^{2}\right)(\mathrm{kubus} / \text { silinder })\end{array}$} & 326,08 & 234,37 & 254,75 & 213,99 \\
\hline
\end{tabular}

(Sumber : Data Diolah)

\section{fc' Rencana}

\begin{tabular}{|c|c|c|c|c|c|c|}
\hline \multirow{2}{*}{\multicolumn{2}{|c|}{$\begin{array}{l}\text { Pelat } \\
\text { fc' Rencana Balok }\end{array}$}} & : & 20,75 & Мра & $=$ & $250 \mathrm{Kg} / \mathrm{cm}^{2}$ \\
\hline & & : & 20,75 & Mpa & $=$ & $250 \mathrm{Kg} / \mathrm{cm}^{2}$ \\
\hline \multirow[t]{3}{*}{ Spesifikasi } & Pelat & : & 280,23 & $\mathrm{Kg} / \mathrm{cm}^{2}$ & $>$ & $250 \mathrm{Kg} / \mathrm{cm}^{2}$ \\
\hline & & & \multicolumn{4}{|c|}{ Sesuai Rencana } \\
\hline & Balok & : & 234,37 & $\mathrm{Kg} / \mathrm{cm}^{2}$ & $<$ & $250 \mathrm{Kg} / \mathrm{cm}^{2}$ \\
\hline
\end{tabular}

Tidak Memenuhi 


\section{KESIMPULAN}

Dari data-data yang diambil dari lapangan dapat disimpulkan bahwa pengecekan kelayakan banguan sekolah menengah atas negeri 1 kota kediri diambil dari kekuatan pelat atap dan balok penyangga pelat dengan menggunakan hammer test, maka didapatlah nilai dari perhitungan ;

fc' Rencana

Pelat

fc' Rencana Balok

Spesifikasi

Pelat :

Balok :

$\begin{array}{cc}20,75 \mathrm{Mpa} & = \\ 20,75 \mathrm{Mpa} & = \\ 280,23 \mathrm{Kg} / \mathrm{cm}^{2} & >\end{array}$

Sesuai Rencana

$234,37 \mathrm{Kg} / \mathrm{cm}^{2} \quad<$
$250 \mathrm{Kg} / \mathrm{cm}^{2}$

$250 \mathrm{Kg} / \mathrm{cm}^{2}$

$250 \mathrm{Kg} / \mathrm{cm}^{2}$

$250 \mathrm{Kg} / \mathrm{cm}^{2}$

Tidak Memenuhi

\section{SARAN}

Dari kesimpulan dapat kiata rekomendasikan bahwa bangunan sekolah menengah atas negeri 1 kota kediri sebagai berikut :

1. Tidak layak utuk diteruskan pembangunannya atau penambahan lantai bangunan.

2. Penambahan kolom pada jion balok .

3. Mengganti balok dan penambahan tulangan ( balok existing dibongkar diganti tulangan baru dan dicor kembali) 


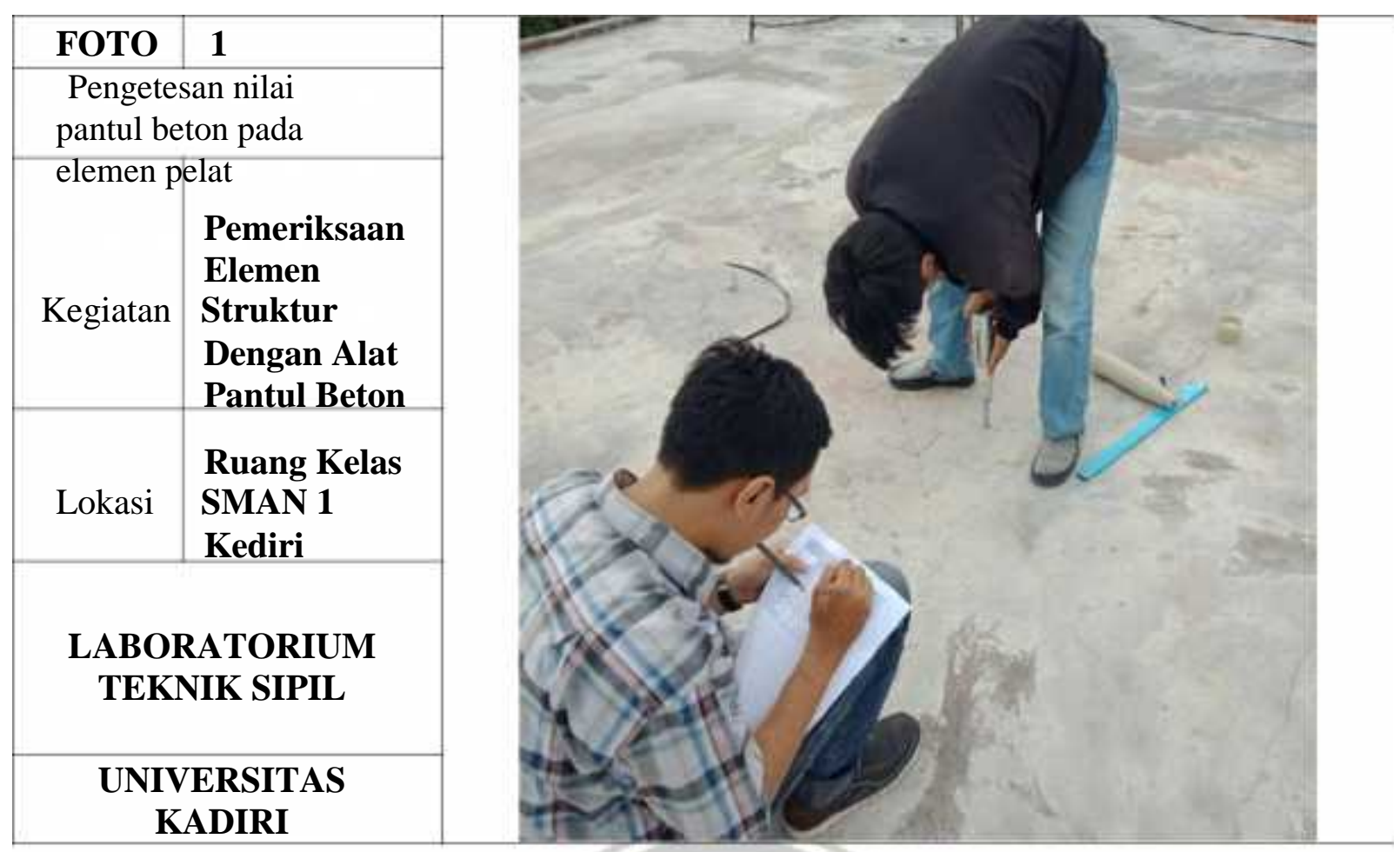

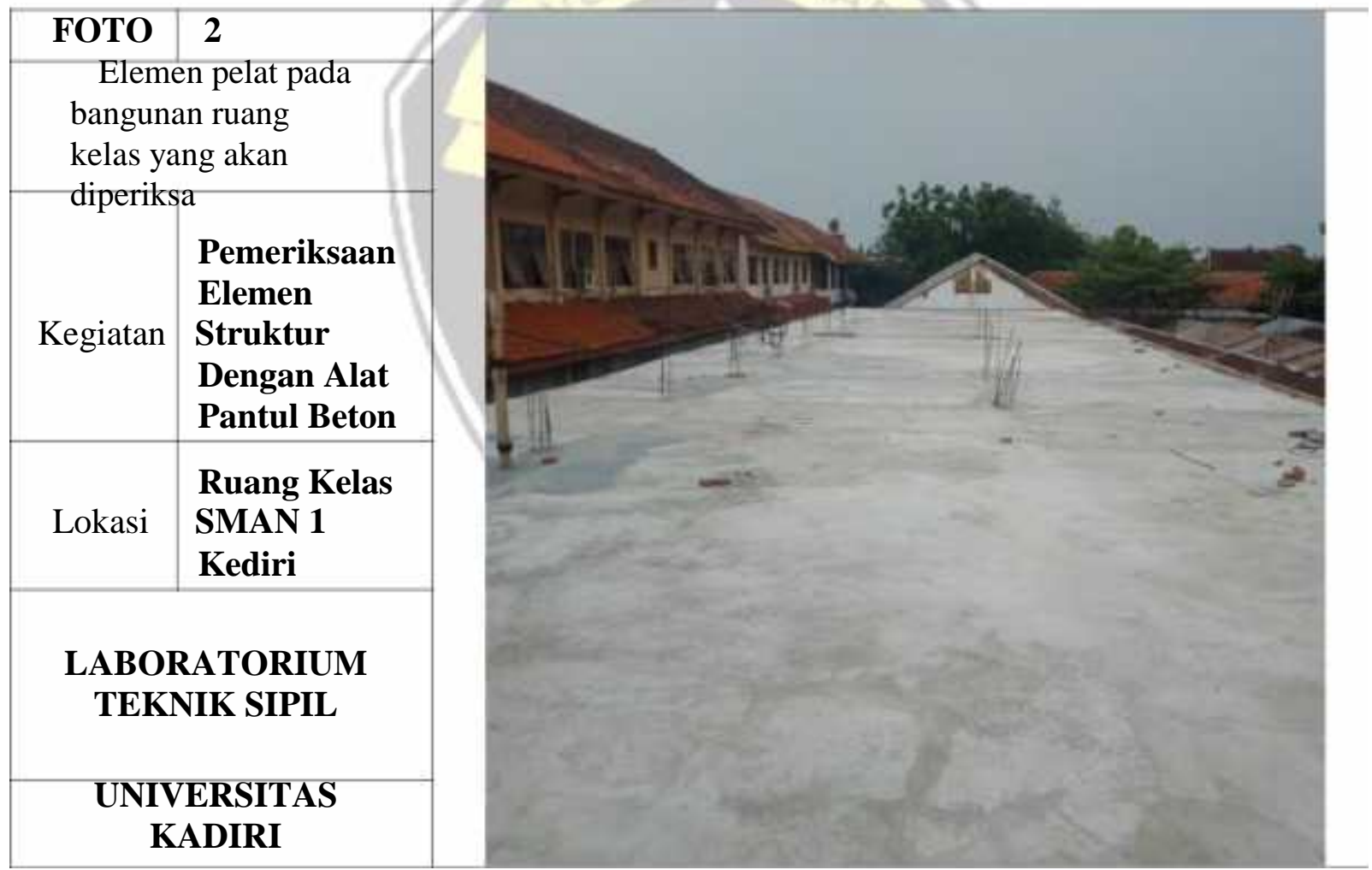




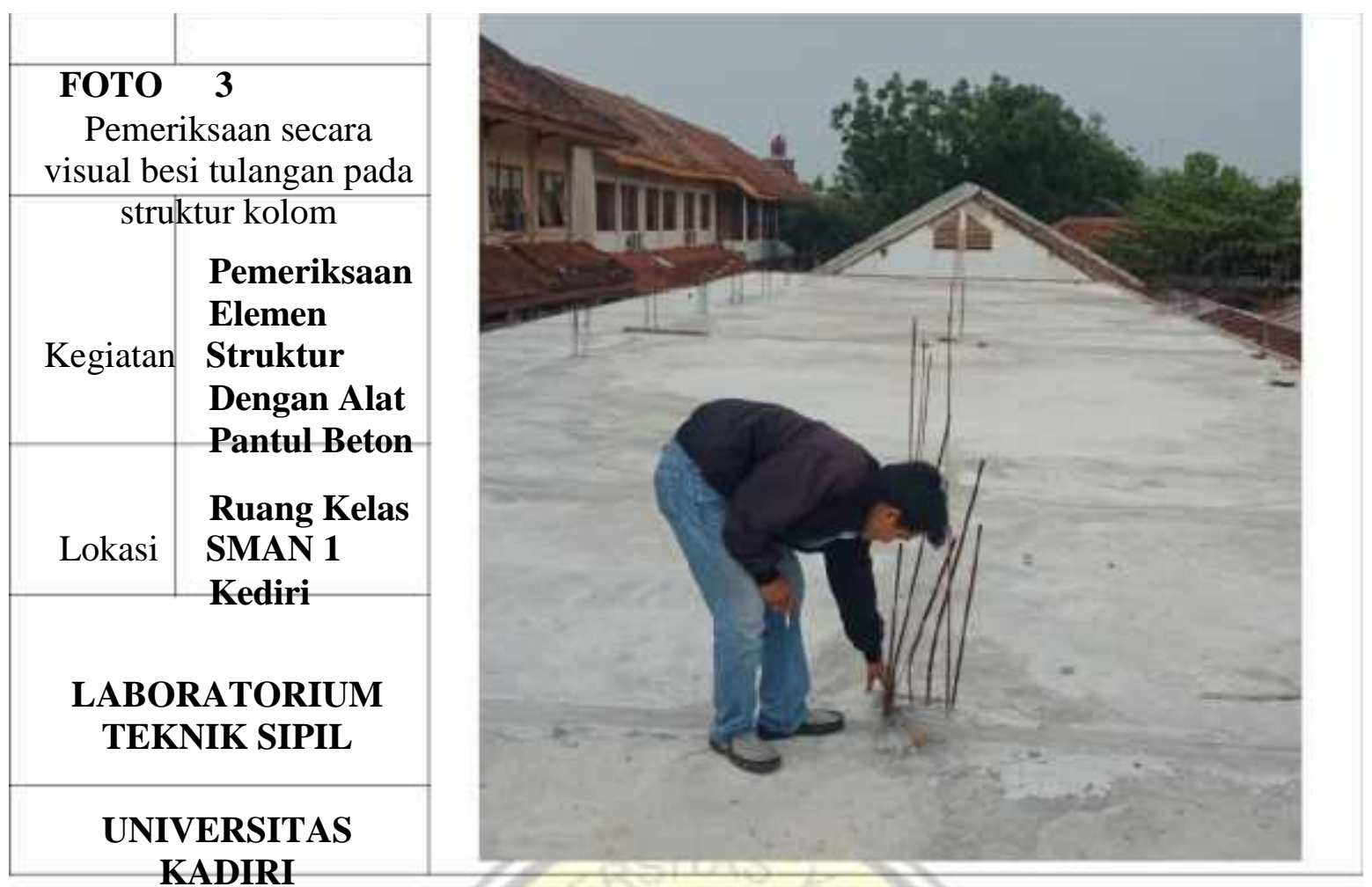

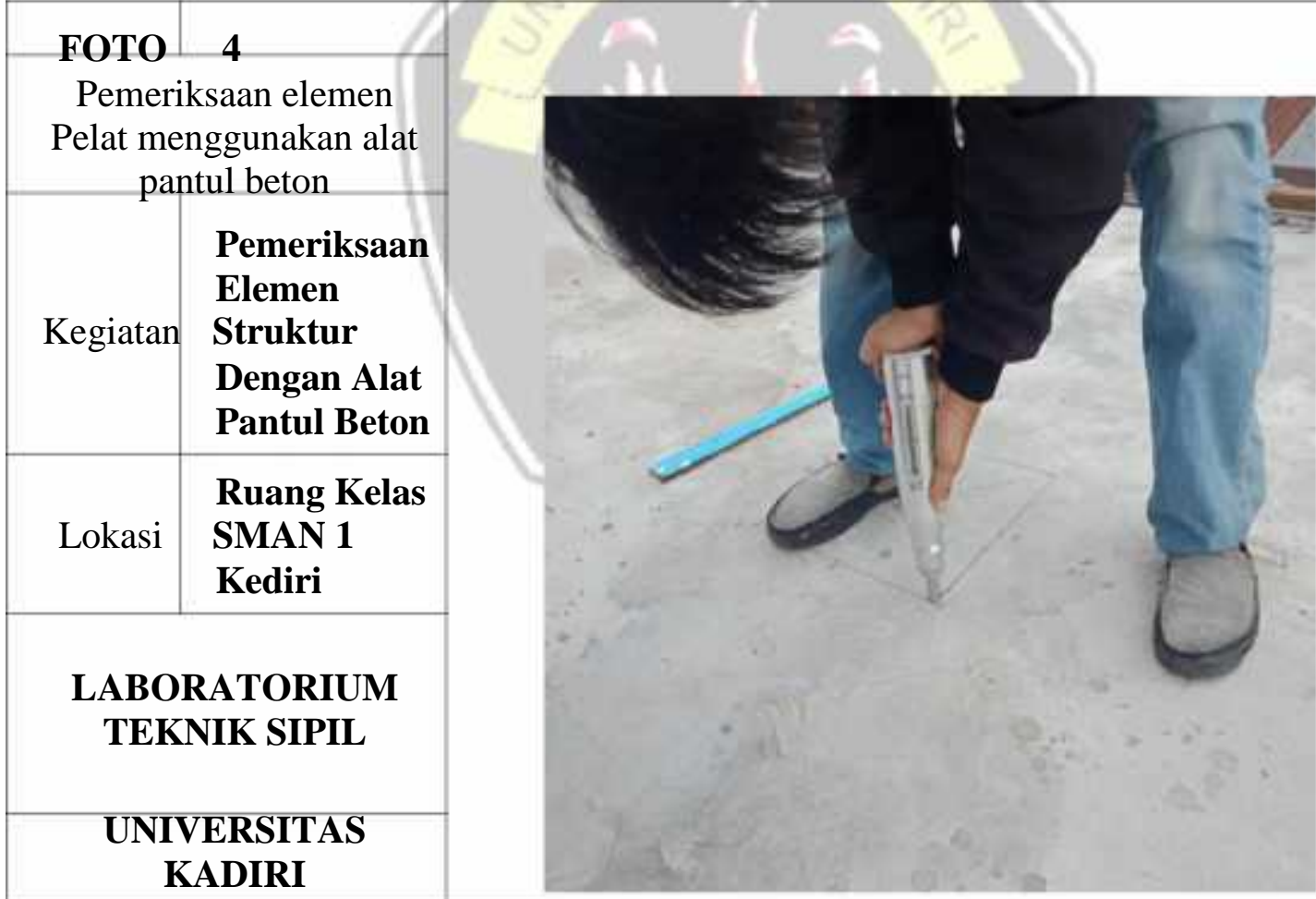




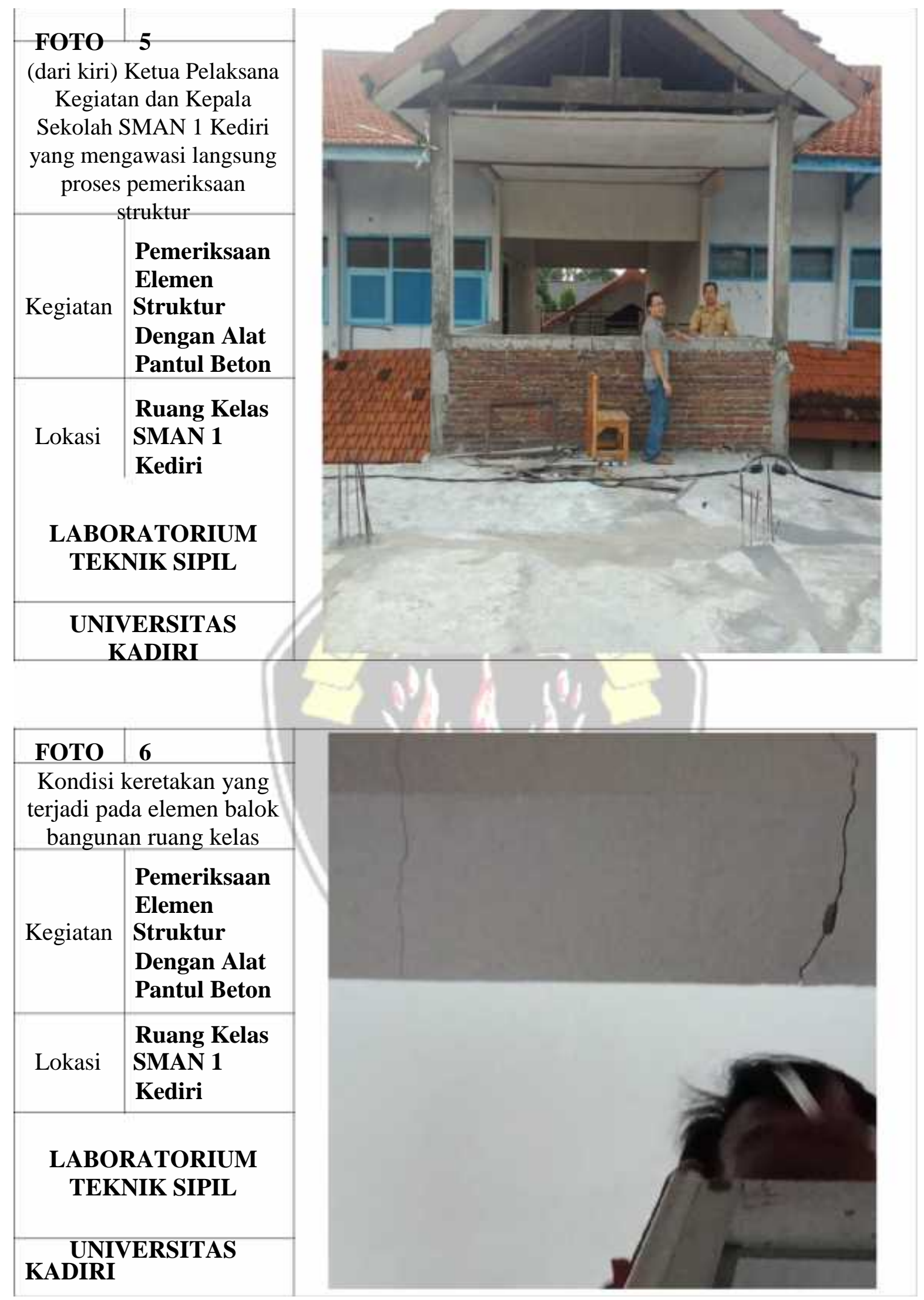




\section{DAFTRAR PUSTAKA}

https://hesa.co.id/uji-kekuatan-beton-dengan-hammer-test/

http://staffnew.uny.ac.id/upload/132256207/pendidikan/rsni-4803200xxastm-c80502.pdf PBI 1971 N.I.-2 ke SNI 03-2847-2002

https://www.ikons.id/pengujian-struktur-beton-dengan-metoda-hammer-test-metoda-ujipembebanan-load-test/

https://www.alatuji.com/index.php?/article/detail/426/test-hammer-alat-untuk-mengukurkekuatan-beton

https://sanggapramana.wordpress.com/2010/08/03/sistem-penulangan-pelat/

https://www.mitrarenov.com/berita/dinding-rumah-baru-anda-retak-berikut-penyebab-dansolusinya.

https://www.academia.edu/33170295/PERENCANAAN_STRUKTUR_GEDUNG_RUANG _BELAJAR_SEKOLAH_MENENGAH_ATAS_3_LANTAI_DI_PROVINSI_RIAU

https://eprints.uns.ac.id/10783/1/Unlock-d_(13).pdf 